\title{
Physical Activity Why and How?
}

\section{Marie Alricsson*}

Department of Health Sciences, Mid Sweden University, Sweden

Human beings are designed for physical activity. Human movement is positively related to health. The physically active life-style has changed and it seems that many people are not sufficiently active.

Physical activity is often defined as any bodily movement produced by skeletal muscles that require energy expenditure [1]. Physical activity also means a multidimensional behaviour defined as "the behaviour that involves human movement, resulting in physiological attributes including increased energy expenditure and improved physical fitness" [2].

Physical fitness includes both health and skill related fitness. Muscular endurance, muscular strength, cardiorespiratory endurance, body composition and flexibility are examples of health related components of physical fitness whereas agility, balance, coordination, speed, power and reaction time are examples of skill related components [1].

Modern physical activity research began in the 1950s with the studies by Morris and colleagues on bus drivers and conductors [3]. Today there is strong scientific evidence that regular physical activity promoting health and preventing many chronic diseases. [4-7]. Physical activity has multifactorial effects, meaning that it affects many systems in the body at the same time and can thereby influence both physical and mental health $[4,8-12]$.

The effect of physical activity is dose dependent in terms of frequency, duration, intensity and type of physical activity and can be measured with different kind of subjective and objective methods [1315]. Physical activity is complex, meaning that it is difficult to measure in an objective way. It can be measured directly (heart rate monitor) or indirectly (self-reported questionnaires). Self-reported physical activity and self-administered recall questionnaires are the most used methods to assess physical activity behaviour [16-17].

A retrospective questionnaire can be used to recall what physical activities that were completed over the day or during a longer period. Recall bias may exist and self-reported physical activity could be overor underreported [18].

The guidelines for physical activity have changed over time. Earlier recommendations focused on high intensity physical activity whereas nowadays the recommendations focus on more moderate intensity physical activity lifestyle to improve health [19]. The current guidelines for adolescents involve 60 minutes or more of either moderate or vigorous intensive physical activity per day, and more than 60 minutes provides additional health benefits. The majority of these physical activities should be aerobic-type activities. At least three times a week adolescents should be engaged in physical activity of vigorous intensity, including those that strengthen muscles and bones [5-7].

The Swedish recommendation for the population is that: "All individuals should be physically active for a combined minimum of 30 minutes, preferably every day. The intensity should at least be moderate, such as a brisk walk. Additional health effects can be achieved if the daily amount or intensity is increased beyond this." In order to affect various diseases, an individually adapted recommendation is needed that takes each individual circumstance into account [20].
It has been reported that causes of mortality are delayed if regular physical activity is carried out, and that benefits are associated with higher amounts of physical activity in a dose-response relationship [21]. Physically inactive subjects, who are unwilling or unable to meet physical activity recommendations, however still can get health benefits from being engaged in less physical activity than the recommendations; "some is good, more is better" [21].

This has led researchers to search new ways to tackle the problem and for a greater understanding of the effect of the physical activity.

\section{References}

1. Caspersen CJ, Powell KE, Christenson GM (1985) Physical activity, exercise and physical fitness: definitions and distinctions for health-related research. Public Health Rep 100: 126-131.

2. Pettee Gabriel KK, Morrow JR Jr, Woolsey AL (2012) Framework for physical activity as a complex and multidimensional behavior. J Phys Act Health 9 Supp 1: S11-S18.

3. Morris JN, Heady JA, Raffle PA, Roberts CG, Parks JW, et al. (1953) Coronary heart-disease and physical activity of work. Lancet 262: 1111-1120.

4. Martin BW, Kahlmeier S, Racioppi F, Bergman F, Meitinen M, et al. (2006) Evidence-based physical activity promotion - HEPA Europe, the European Network for the promotion of Health - Enhancing Physical Activity. Public Health 14: 53-57.

5. U.S Department of Health and Human Services (2008) Physical activity guidelines for Americans. Be active, healthy, and happy, USA

6. World Health Organization (WHO) (2010) Global recommendations on physical activity for health.

7. Centers for Disease Control and Prevention (CDC) (2011) School health guidelines to promote healthy eating and physical activity. MMWR Recomm Rep 60: 1-76.

8. Powell KE, Thompson PD, Caspersen CJ, Kendrick JS (1987) Physical activity and the incidence of coronary heart disease. Annu Rev Public Health 8: 253287

9. Fox KR (1999) The influence of physical activity on mental well-being. Public Health Nutr 2: 411-418.

10. Lawlor DA, Hopker SW (2001) The effectiveness of exercise as an intervention in the management of depression: systematic review and meta-regression analysis of randomised controlled trials. BMJ 322: 763-767.

11. Van Der Horst K, Paw MJ, Twisk JW, Van Mechelen W (2007) A brief review on correlates of physical activity and sedentariness in youth. Med Sci Sports Exerc 39: 1241-1250.

12. Bouchard C, Blair SN, Haskell WL (2012) Physical activity and health (2nd ed) Champaign, IL: Human Kinetics.

*Corresponding author: Marie Alricsson, Department of Health Sciences Mid Sweden University, Sweden, E-mail: Marie.Alricsson@miun.se

Received August 15, 2013; Accepted August 17, 2013; Published August 19, 2013

Citation: Alricsson M (2013) Physical Activity Why and How? J Biosafety Health Educ 1: e111. doi:10.4172/2332-0893.1000e111

Copyright: (c) 2013 Alricsson M. This is an open-access article distributed unde the terms of the Creative Commons Attribution License, which permits unrestricted use, distribution, and reproduction in any medium, provided the original author and source are credited. 
13. Haskell WL (1994) J.B. Wolffe Memorial Lecture. Health consequences of physical activity: understanding and challenges regarding dose-response. Med Sci Sports Exerc 26: 649-660.

14. Haskell WL (2001) What to look for in assessing responsiveness to exercise in a health context. Med Sci Sports Exerc 33: S454-S458.

15. Oja $P$ (2001) Dose response between total volume of physical activity and health and fitness. Med Sci Sports Exerc 33: S428-S437.

16. Sallis JF, Saelens BE (2000) Assessment of physical activity by self-report: status, limitations, and future directions. Res Q Exerc Sport 71: S1-S14.

17. Haskell WL (2012) Physical activity by self-report: a brief history and future issues. J Phys Act Health 9 Suppl 1: S5-S10.
18. Ekelund U, Tomkinson G, Armstrong N (2011) What proportion of youth are physically active? Measurement issues, levels and recent time trends. $\mathrm{Br} J$ Sports Med 45: 859-865.

19. American College of Sport Medicine (ACSM) (2010) Resource manual for guidelines for exercise testing and prescription. Lippincott Williams \& Wilkins, Baltimore.

20. Swedish National Institute of Public Health (2010) Individually Adapted, Written Prescription of Physical Activity-FAR.

21. Garber CE, Blissmer B, Deschenes MR, Franklin BA, Lamonte MJ, et al. (2011) American College of Sports Medicine position stand. Quantity and quality of exercise for developing and maintaining cardiorespiratory, musculoskeletal and neuromotor fitness in apparently healthy adults: guidance for prescribing exercise. Med Sci Sports Exerc 43: 1334-1359. 